\title{
Forming Suitable Groups in MCSCL Environments
}

\author{
Sofiane Amara, University of Sciences and Technology of Oran "Mohamed Boudiaf” (USTO- MB), Algeria \\ Fatima Bendella, University of Sciences and Technology of Oran "Mohamed Boudiaf” (USTO- MB), Algeria \\ Joaquim Macedo, University of Minho, Portugal
}

Alexandre Santos, University of Minho, Portugal

\begin{abstract}
Given the peculiarities of mobile computer-supported collaborative learning (MCSCL) environments, forming suitable groups in such learning environments represents a hard and time-consuming task. This is because many conditions related to mobile learners, devices, and environment should be considered. Unlike the existing solutions, the present paper shows a grouping approach that allows a customizable formation of (1) homogeneous groups, (2) heterogeneous groups, and (3) mixed groups. The proposed solution does not only help instructors to dynamically form appropriate MCSCL groups, but it also allows to continually control the learners' learning, psychological, and social developments. To assess the effectiveness of the proposed solution, three metrics were used: (1) comparison between the characteristics of the existing group formation tools, (2) average intra-cluster distance of each grouping algorithm, and (3) an experimental evaluation in a real world environment. The obtained results show a great superiority of the proposed solution compared to the existing ones.
\end{abstract}

\section{KEYWORDS}

Collaborative Learning, Group Formation, Grouping Algorithms, MCSCL, Mobile Learning

\section{INTRODUCTION}

Collaborative learning (CL) is a process in which two or more learners work together to achieve certain common learning objectives. For instance, to obtain, construct, or share new knowledge; to resolve some problems; to develop some projects, etc. CL could effectively help learners to develop their personal and social skills that could not be achieved individually, such as "making ideas explicit, communicating with others, reasoning, arguing and negotiating" (Carro, 2008, p. 3). Many other researchers have demonstrated the importance of CL (Dillenbourg, 1999; Johnson \& Johnson 1994; Roger \& Johnson, 1994; Yadegaridehkordi et al., 2019; Zurita et al., 2005).

The development of information and communication technologies (ICT) has led to the emergence of "E-learning", which is based on the use of ICT to facilitate the tasks of constructing and sharing knowledge. The educators began then to search how to benefit from the rapid evolution of ICT to improve the CL pedagogy. As result, since the late 1990s, a new branch of learning called Computer 
Supported Collaborative Learning (CSCL) has emerged (Lai, 2011). CSCL represents a pedagogical approach that aims to promote the collaboration between learners by helping them to construct their knowledge using computers and networks as their principal means of communication.

As part of ICT, the use of mobile communication technologies in last years has greatly expanded. According to the 2018's annual data and statistics report published by the International Telecommunication Union agency (ITU), the rate of mobile-cellular telephone subscriptions has been increased from 15\% in 2001 to $107 \%$ in 2018 (ITU, 2018) (see Figure 1). According to the same report, the penetration of mobile broadband in the world reaches $69.3 \%$ in 2018 . This value has increased 12 times since 2007. This explosive growth in the usage of mobile technologies has led to the appearance of mobile learning (M-learning). In such a learning model, learners use only mobile devices (e.g., Smartphones, tablets, PDA) to learn anywhere and anytime.

Combining the two learning paradigms ( $\mathrm{CL}$ and M-learning) in one process permitted the appearance of a new learning domain called Mobile Computer Supported Collaborative Learning (MCSCL). MCSCL allows mobile learners to collaboratively obtain, construct and share their knowledge without the constraints of place and time.

As demonstrated by many researchers, a successful CL is the one that is based principally on the formation of effective learning groups (Dillenbourg, 1999; Huang \& Wu, 2011; Webb et al., 1998). However, having such successful groups requires a lot of efforts and time, especially when the number of learners is considerable. Compared to traditional learning environments, the group formation issue in MCSCL context represents more hard and time-consuming task. Instructors should not consider only the personality traits of learners (age, gender, cultures, skills, etc), but also their various learning behaviours (communication, movements, preferences, learning styles, etc), and information that are related to learning contexts (location, time, availability, etc). Therefore, the main challenge of this study is to provide the MCSCL community with a new automatic, dynamic, and customizable group formation solution that could enhance the learning, psychological, and social development of learners. To well achieve this objective, the following research questions should be clearly answered:

- Question 1: Which grouping criteria could affect the learning quality of created groups?

- Question 2: How a grouping algorithm should be developed in MCSCL environments?

- Question 3: How to evaluate the effectiveness of the proposed group formation solution?

The rest of paper is organized as follows: section 2 presents some interesting related works. Section 3 describes the proposed group formation approach. Section 4 shows the proposed grouping algorithms. Section 5 describes the evaluation of the proposed approach. Section 6 presents the limitations of the study. Finally, conclusions and recommendation for future works are provided in section 7.

\section{RELEVANT RESEARCH}

Many solutions have been proposed in literature to deal with the problem of learning group formation in MCSCL environments. Among the most relevant studies, there is the solution proposed by (Huang $\& \mathrm{Wu}, 2011)$, that developed a systematic grouping method that records learners' behaviors data in learning portfolios, and forms heterogeneous groups based on the stored data. (Mujkanovic et al., 2012) demonstrated that using some specific grouping criteria (learners' characteristics) could help to obtain desired outcomes. (Yin et al., 2012), (Tan et al, 2010), (Yamamoto \& Uchida, 2018), and (Zurita et al, 2005) implemented collaborative learning environments to support dynamic grouping of learners in real-time. (El-Bishouty et al., 2010), (Hsieh et al., 2010), and (Huang et al., 2010) proposed grouping systems that use the level of social interaction between learners as grouping criteria. (Messeguer et al., 2010) developed an intelligent system that uses contextual information 


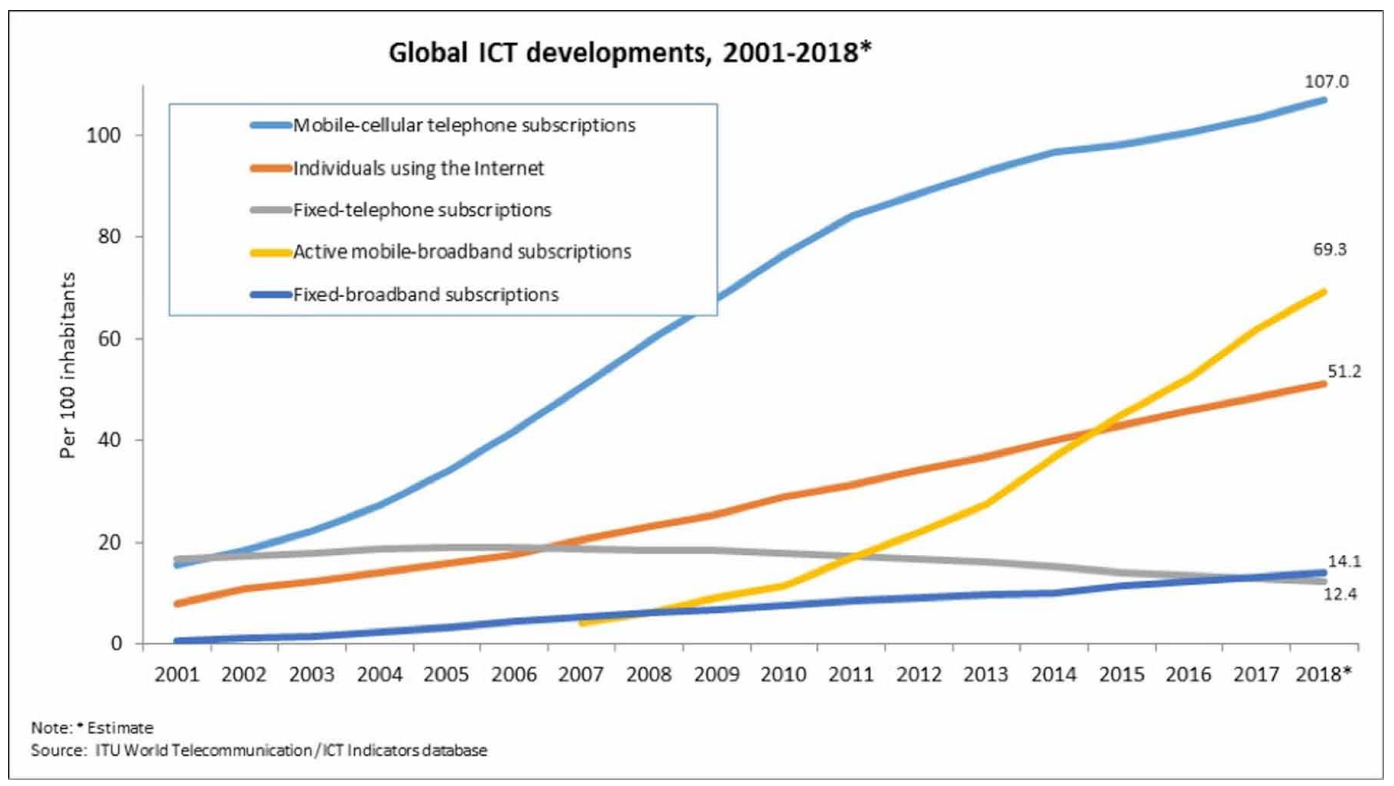

from students' devices to estimate group membership. (Mballo, et al., 2017) proposed a grouping method based on the level of learners mobility.

The learning groups in MCSCL environments can be created according to three types of grouping criteria: (a) the learner's personal characteristics, (b) the learner's behaviours, and (c) the learning context information (Amara et al, 2016). However, all the proposed studies use only few grouping criteria, and there is no solution that considers the three kinds of grouping criteria in one grouping process.

In many learning situations, instructors need to introduce their specific requirements, such as the grouping criteria, the nature of groups, the size of groups, etc. However, the majority of proposed solutions does not allow instructors to customize the grouping process.

Furthermore, the majority of existing studies is unable to provide a possibility to re-build learning groups in real time. Such a dynamic regrouping is very useful for reaching the benefits of CL.

\section{THE PROPOSED GROUP FORMATION APPROACH}

In light of the literature review findings, the researchers propose a new approach for dynamically build heterogeneous, homogeneous and mixed groups of mobile learners. The proposed approach takes into consideration the combination of the three types of criteria in one grouping process. Such a combination makes the proposed solution more adaptable for different situations. Moreover, the proposed solution gives instructors a flexible mean to control the developments of their learners through the continuous storage of different types of data (learners' capacities, learners' achievement, learning outcomes, etc).

Unlike the existing studies, which handicap instructors to choose the relevant grouping criteria, the proposed solution gives them the possibility to customize the group formation process. That means that instructors are able to chose between many available grouping criteria. The proposed solution is based on the idea that a useful grouping mechanism should not be specific for a particular type of learners or situations; it should not be related to a particular criterion; and it should not provide only one type of grouping (homogeneous or heterogeneous groups). To achieve this objective, the proposed 
Table 1. Used group formation criteria

\begin{tabular}{|l|l|l|}
\hline Personal characteristics & \multicolumn{1}{|c|}{ Learning behaviours } & \multicolumn{1}{c|}{ Context information } \\
\hline Age & . Communication with partners & - Locations of learners \\
$\cdot$ Gender & - Communication with instructor & - Location of learning objects \\
$\cdot$ Mother languages & - Interaction with learning objects & - Time of learning \\
$\cdot$ Mastered languages & - Learning style & - Learner availability \\
$\cdot$ Academic performance & & - Learning objects availability \\
\hline
\end{tabular}

approach allows instructors to customize the task of forming groups according to different scenarios, activities, learners, needs, objectives, etc. Table 1 shows the set of grouping criteria considered for this study. Some of those criteria are selected from the literature review study conducted by (Amara et al, 2016).

\section{Dynamic Grouping}

A suitable group formation mechanism should not be specific for certain types of learners or learning, but it should be useful for different learning objectives, needs, and scenarios. To reach this goal, the proposed tool is developed to be used in different situations. Among the possible situations is when a new learner comes late and searches for a learning group; Or when a learner finds difficulties (social, learning, cultural, etc) with his/her partners and wants to change the group; Or when a learner lost contact with his/her group mates due to technical or geographical barriers. In all of those cases, dynamic group formation process helps learners to quickly find new appropriate groups according to the updated values of their learning, social, and personal information.

\section{Customizable Process}

There are no specific grouping criteria that could be considered as optimal for any CL activity. The choice of the best criteria should depend on the type of target populations, the nature of the collaborative activities, the needs, the objectives, the place and time of learning. Indeed, an effective group formation process should help instructors to easily customize the grouping mechanism. Thus, one of the objectives of the proposed solution is to provide instructors with a flexible tool with a greatest possible number of grouping criteria, in order to allow them to select the criteria that could adapt the different situations.

\section{Continuous Monitoring of Learners Development}

The proposed solution allows instructors to continuously control the learning and social developments of their learners. To reach this goal, the proposed system stores the learning information of learners (marks, levels, competences, etc); and also their psychological and social information (preferences, communication with others, etc). Furthermore, the system saves more information related to MCSCL environments such as preferred places, preferred devices, preferred applications, etc.

\section{Group formation algorithm}

As previously described, one of the advantages of the proposed group formation solution resides in its capacity to provide instructors with a customizable tool, which could be used for different learning situations. To achieve this objective, the authors considered the three possible kinds of grouping: (a) homogeneous grouping, (b) heterogeneous grouping, (c) mixed grouping.

\section{The Learner Space}

To have a clear comparison between learners' attributes, the researchers applied the concept of vector space model, where each learner is represented by a vector in a multidimensional space. The number 
and the type of the used dimensions are given by instructors according to different learning situations. For instance, if instructor considers three grouping criteria; age, gender and level of communication with partners; then each learner should be represented as a vector $L\left(C_{1}, C_{2}, C_{3}\right)$, where $C_{1}$ represents the age of this learner, $C_{2}$ represents his/her gender, and $C_{3}$ represents his/her communication level with partners.

Another important step before executing the grouping algorithm is related to the data normalization problem, because the attributes of learners are represented in different measurement scales. For example, the age values are between 14 to 20, the gender values are between 0 (female) to 1 (male), the communication level values are between 0 to 5 , etc. Therefore, the researchers added a normalization process that serves to bring all the considered attributes to the same scale. To accomplish the desired normalization, the researchers adopted the min-max normalization method proposed by (Jain \& Bhandare, 2011). The developed normalization process turns a given vector $L$ $\left(C_{1}, C_{2},,, C_{n}\right)$ into a new vector $L^{\prime}\left(C_{1}, C_{2}{ }^{\prime},,, C^{\prime}{ }_{n}\right)$. The value $d$ ' of each new attribute $C^{\prime}$ is calculated using the formula (1).

$$
d^{\prime}=\frac{d-\min (C)}{\max (C)-\min (C)}
$$

Where $d$ represents the old value of the attribute, $\min (\mathrm{C})$ represents the minimum value between all the data of the attribute $\mathrm{C}, \max (\mathrm{C})$ represents the maximum value between all the data of the attribute C. For example, let the ages data of learners is: $C=\{15,14,18,20,16\}$. The minimum value in this example is $\min (C)=14$, and the maximum value is $\max (C)=20$. Then the normalized data is:

$$
C_{1}^{\prime}=\left\{\frac{15-14}{20-14}, \frac{14-14}{20-14}, \frac{18-14}{20-14}, \frac{20-14}{20-14}, \frac{16-14}{20-14}\right\}=\{0.16,0,0.66,1,0.33\}
$$

\section{Homogeneous Grouping Algorithm}

The proposed grouping algorithms are principally based on the calculation of Euclidian distances between learners' attributes. The Euclidian distance between two learners L1 and L2 is presented with formula (2).

$$
D\left(L_{1}, L_{2}\right)=D\left(L_{2}, L_{1}\right)=\sqrt{\sum_{i=1}^{n}\left(C_{i, l}-c_{i, 2}\right)^{2}}
$$

Where $\mathrm{C}_{\mathrm{i} .1}$ represents the value of the $\mathrm{I}$ th attribute of learner $\mathrm{L}_{1}$, and $\mathrm{C}_{\mathrm{i} .2}$ represents the value of the $\mathrm{I} t h$ attribute of learner $\mathrm{L}_{2}$. And $\mathrm{n}$ represents the number of the considered attributes.

Homogeneous grouping algorithm serves to form groups of learners with the most similar features. To achieve this objective the algorithm follows the following phases:

Phase A: The algorithm receives the grouping settings from the instructor's device, such as: the number of groups, the list of grouping criteria, and the type of groups.

Phase B: According to the number of groups given by instructor, the algorithm selects randomly some learners to be the centroids of clusters (groups), and uses the attributes' values (criteria) of the selected learners as the initial clusters means. 
Phase C: The algorithm examines the data related to every learner, calculates the Euclidean distances between him/her and all the clusters' centroids, and allocates him/her to the closer cluster.

Phase D: after each allocation of any learner to a new cluster, the algorithm recalculates the new centroid vector of the last and the new cluster of this learner.

Phase E: after the allocation of all learners to their clusters, the algorithm verifies if every learner was assigned to his appropriate group using the Euclidean distance. If not, the algorithm should repeat the phases $\mathrm{B}, \mathrm{C}$, and $\mathrm{D}$, until no change appears in the groups' members.

Phase F: sometimes it's possible that the algorithm cannot find the best solution (no stop in repetition of phases B, C, and D). In this case, the execution of the algorithm should be stopped after a predefined number of iterations.

\section{Heterogeneous Grouping Algorithm}

Heterogeneous grouping algorithm aims to form groups of learners with the most different features. The developed algorithm follows the following phases:

- Phase A: The algorithm receives the grouping settings from the instructor's device, such as: the number of groups, the list of grouping criteria, and the type of grouping.

- Phase B: By calculating the distances between all the participated learners (using formula 2), the grouping algorithm creates a similarity matrix that is represented as a table of $n$ rows and $n$ columns, where $\mathrm{n}$ is the number of learners.

- Phase C: To form a heterogeneous group, the algorithm selects from the similarity matrix the two learners with the greatest distance value. Then it calculates the mean vector of this group using the attributes' values of the two selected learners, and removes them from the similarity matrix.

- Phase D: In this phase the algorithm:

1. Calculates the distances between the mean vector of the created group and the rest of learners;

2. Finds the learner that had the greatest distance value with the mean vector;

3. Adds the selected learner to the created group;

4. Removes the selected learner from the similarity matrix;

5. Calculates the new mean vector of the formed group.

- Phase E: The phase D is repeated until reaching the requested number of learners in the group.

- Phase F: The phases C, D, E are repeated until removing all learners from the similarity matrix.

\section{Mixed Grouping Algorithm}

While all the grouping methods existing in literature permit the formation of only one type of learning groups (homogeneous or heterogeneous learning groups), the method proposed in this study allows the formation of mixed groups. That means that the grouping algorithm could form groups that are homogeneous in terms of certain criteria and heterogeneous for other ones. For instance, forming groups that are homogenous in terms of gender (only males or females in a same group) and heterogeneous in terms of learning styles (learners with different learning styles in a same group).

The mixed grouping algorithm aims to classify learners in a set of hierarchical steps. In each step, a given criterion is used, and a given grouping method is followed. For instance, first the algorithm classifies learners based on their geographical locations in a set of main groups. Then, each created group would be divided in a set of subgroups based on the learners' gender. Then each created subgroup would be divided in small groups based on the learners' interaction level, and so on.

Using such a grouping mechanism, instructors would be able to select the grouping criteria in a priority manner. He/she could first classify learners using the highest priority criteria (the criteria that he/she finds them most important according to a given need or situation). Then he/she uses successively the rest of criteria according to their priority to create new groups from the existing ones.

The proposed mixed grouping algorithm follows the following phases: 
1. The algorithm receives the grouping settings from the instructor's device, such as: the number of groups or the maximum number of learners in each group; the list of grouping criteria in a priority manner; and the type of grouping for each criterion (homogeneous or heterogeneous).

2. The algorithm creates a set of main groups of learners, using the criterion of the high priority, and the type of grouping related to this criterion.

3. After the creation of the main groups, the algorithm divides each one of them to a set of subgroups, according to the criterion provided by instructor.

4. Each created subgroup can be also divided in a set of small groups using another criterion.

To form the groups in steps 2, 3 and 4, the homogeneous and heterogeneous algorithms are followed.

\section{EVALUATION}

\section{Evaluation Based on The Characteristics of Group Formation Tools}

Table 2 shows a general comparison between the existing group formation solutions. This comparative study was principally conducted by (Amara et al, 2016), and the researchers added two new approaches that are recently proposed by (Mballo, et al., 2017) and (Yamamoto \& Uchida, 2018).

First, one can see that all the existing solutions can form only one type of groups (Heterogeneous or Homogeneous groups). The proposed study is the only one that allows instructors to chose between the formations of heterogeneous, homogeneous, or mixed groups according to different learning situations.

Regarding the grouping criteria, one can remark that the existing approaches have never considered the three types of grouping criteria (learners' personal characteristics, learners' learning behaviours, and context information) in one tool. The proposed solution is the only one that allows such a combination.

Regarding the characteristics of the existing approaches, one can see that the proposed solution is among the few ones that permit the customization of the grouping process. It gives instructors the possibility to manage the formation of groups according to different situations, objectives, needs, etc.

Another characteristic is the dynamic formation of groups. The proposed solution is among the few approaches that provide the possibility to re-create the learning groups at real time. With such a grouping mechanism, mobile learners could change their learning groups at any moment they want. One of the characteristics that is completely ignored by the existing solution is the continuous control of learners' developments. By storing the different information of learners, the proposed approach allows to control the learning, social, and psychological progress of learners.

\section{Average Intra-Cluster Distance (AID) of The Grouping Algorithm}

In order to make an initial assessment of the group formation solution, a comparison between the effectiveness of the proposed grouping algorithm with other grouping methods has been made with the use of Average Intra-cluster Distance (AID) parameter. AID is used to indicate how much the created groups of a given algorithm are homogeneous or heterogeneous. A high value of AID indicates a high level of heterogeneity, and a low value of AID indicates a high level of homogeneity. To calculate the AID of a grouping algorithm the following steps should be followed:

- (1) For each created group we calculate the sum (S) of total distances between each learner and the other members one by one. The value of $S$ is calculated with formula (3);

- (2) We calculate the AID $_{i}$ of each created group $G_{i}$ by following formula (4);

- (3) We calculate the global AID of the grouping algorithm by dividing the sum of the calculated $\mathrm{AID}_{\mathrm{i}}$ of each group $i$ on the total number of created groups; such is shown in formula (5). 
Table 2. Comparison of the proposed group formation approach with the existing approaches

\begin{tabular}{|c|c|c|c|c|c|c|c|c|c|}
\hline \multirow[b]{2}{*}{ Study } & \multicolumn{3}{|c|}{ Grouping type } & \multicolumn{3}{|c|}{ Group formation criteria } & \multicolumn{3}{|c|}{ Group formation characteristics } \\
\hline & 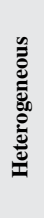 & 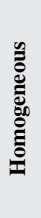 & 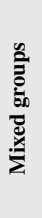 & 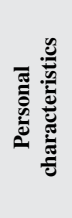 & 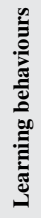 & 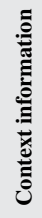 & 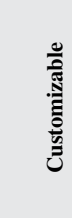 & 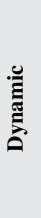 & 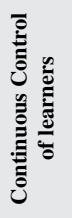 \\
\hline $\begin{array}{c}\text { (Huang \& Wu } \\
\text { 2011) }\end{array}$ & $\checkmark$ & $x$ & $x$ & $x$ & $\checkmark$ & $\checkmark$ & $\checkmark$ & $x$ & $\checkmark$ \\
\hline $\begin{array}{c}\text { (Zurita et al., } \\
\text { 2005) }\end{array}$ & $\checkmark$ & $x$ & $x$ & $\checkmark$ & $x$ & $x$ & $\checkmark$ & $\checkmark$ & $x$ \\
\hline $\begin{array}{c}\text { (Huang et al., } \\
\text { 2010) }\end{array}$ & $x$ & $\checkmark$ & $x$ & $x$ & $\checkmark$ & $x$ & $x$ & $x$ & $x$ \\
\hline $\begin{array}{l}\text { (Messeguer et } \\
\text { al., 2010) }\end{array}$ & $x$ & $x$ & $x$ & $x$ & $\checkmark$ & $\checkmark$ & $x$ & $x$ & $x$ \\
\hline $\begin{array}{c}\text { (El-Bishouty et } \\
\text { al., 2010) }\end{array}$ & $x$ & $x$ & $x$ & $\checkmark$ & $x$ & $\checkmark$ & $x$ & $x$ & $x$ \\
\hline $\begin{array}{l}\text { (Hsieh et al., } \\
\text { 2010) }\end{array}$ & $\checkmark$ & $x$ & $x$ & $\checkmark$ & $\checkmark$ & $\checkmark$ & $x$ & $x$ & $x$ \\
\hline $\begin{array}{l}\text { (Tan et al., } \\
\text { 2010) }\end{array}$ & $x$ & $\checkmark$ & $x$ & $\checkmark$ & $x$ & $\checkmark$ & $x$ & $\checkmark$ & $x$ \\
\hline $\begin{array}{l}\text { (Giemza et al., } \\
\text { 2013) }\end{array}$ & $x$ & $\checkmark$ & $x$ & $\checkmark$ & $\checkmark$ & $x$ & $x$ & $x$ & $x$ \\
\hline $\begin{array}{c}\text { (Mujkanovic et } \\
\text { al., 2012) }\end{array}$ & $x$ & $x$ & $x$ & $\checkmark$ & $x$ & $x$ & $x$ & $x$ & $x$ \\
\hline $\begin{array}{l}\text { (Yin et al., } \\
\text { 2012) }\end{array}$ & $x$ & $\checkmark$ & $x$ & $x$ & $\checkmark$ & $x$ & $x$ & $x$ & $x$ \\
\hline $\begin{array}{c}\text { (Mballo, et al., } \\
\text { 2017) }\end{array}$ & $x$ & $\checkmark$ & $x$ & $\checkmark$ & $\checkmark$ & $x$ & $x$ & $x$ & $x$ \\
\hline $\begin{array}{l}\text { (Yamamoto \& } \\
\text { Uchida, 2018) }\end{array}$ & $x$ & $\checkmark$ & $x$ & $\checkmark$ & $x$ & $x$ & $x$ & $\checkmark$ & $x$ \\
\hline $\begin{array}{l}\text { Proposed } \\
\text { approach }\end{array}$ & $\checkmark$ & $\checkmark$ & $\checkmark$ & $\checkmark$ & $\checkmark$ & $\checkmark$ & $\checkmark$ & $\checkmark$ & $\checkmark$ \\
\hline
\end{tabular}

$s=\sum_{i=1}^{g-1} \sum_{k=i+1}^{g} D\left(L_{i}, L_{k}\right)$

Where $g$ represents the number of learners in the group, and $\mathrm{D}\left(\mathrm{L}_{\mathrm{i}}, \mathrm{L}_{\mathrm{k}}\right)$ represents the distance between learner $i$ and learner $k$.

$$
A I D i=\frac{S i}{\frac{G i !}{2 !(G i-2) !}}
$$

Where $\mathrm{S}_{\mathrm{i}}$ represents the sum of total distances between learners of group $i$, which is calculated using formula (3). $\mathrm{G}_{\mathrm{i}}$ represents the number of learners of group $i$. 
Figure 2. AID's values of groups created by the proposed homogeneous grouping algorithm compared to random grouping
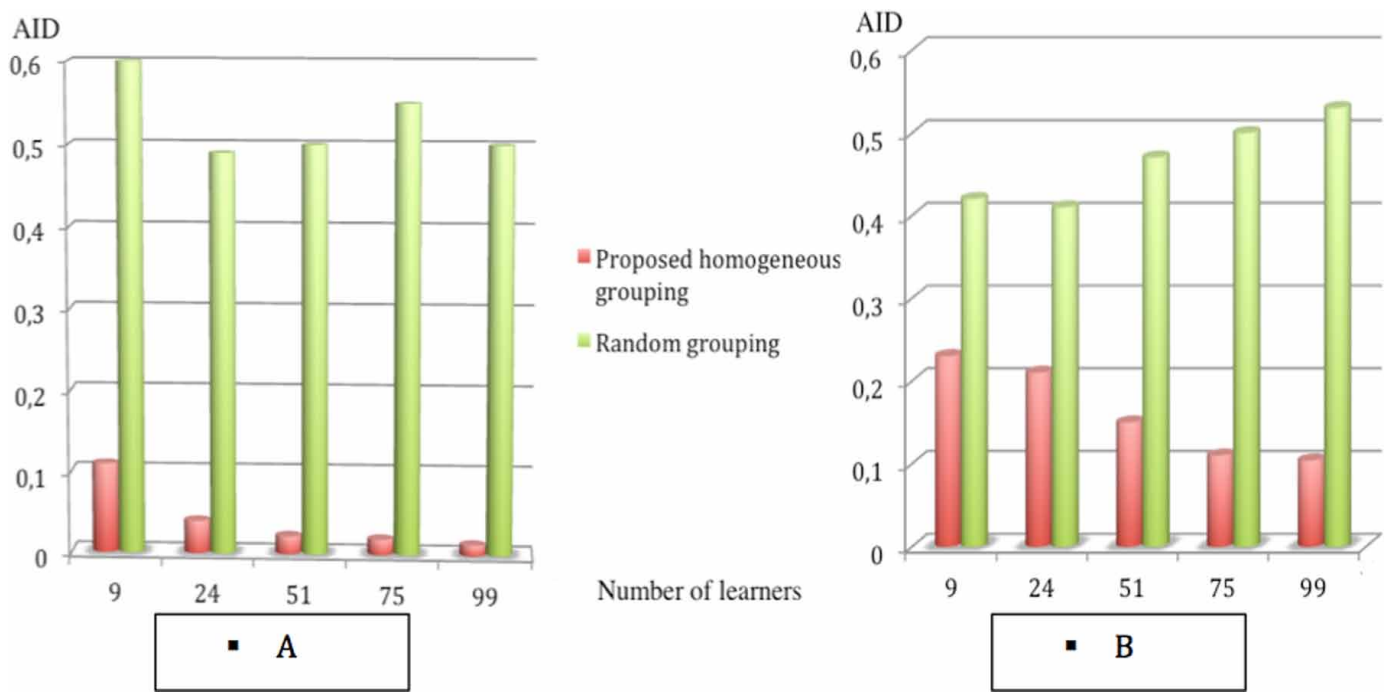

$A I D=\frac{\sum_{i=1}^{n} A I D_{i}}{n}$

$\mathrm{AID}_{\mathrm{i}}$ represents the value of the average intra-cluster distance of group $i$. And $n$ represents the total number of created groups.

Figure 2 (A) shows a comparison between the AID values of groups created by the proposed homogeneous grouping algorithm, with the AID values of groups that are randomly created. In this evaluation step only one grouping criterion was used for both grouping methods. One can remark that the proposed algorithm forms always groups with very law values of AID, whatever the number of learners.

Figure 2 (B) shows a same comparison but with multiple grouping criteria. The obtained results affirm that even with a large number of grouping criteria the proposed algorithm forms always groups with a very high level of homogeneity. There is also a very slight rise in the values of AID related to the proposed algorithm. This is due to use of multiple grouping criteria. Because the more we use a big number of grouping criteria, the more we grow the possibility to increase the distances between learners.

Figure 3 (A) shows a comparison between the AID's values of groups created by the proposed heterogeneous grouping algorithm with those of a grouping solution proposed by (Zurita et al., 2005), considering a unique criterion. The obtained results affirm that when we consider a unique grouping criterion the learning groups created by the proposed algorithm show always a higher level of AID. That means that the proposed algorithm creates always the most possible heterogeneous groups.

Figure 3 (B) represents a comparison between the AID's values of groups created by the proposed heterogeneous algorithm with those of grouping solution proposed by (Huang \& Wu, 2011) using multiple grouping criteria. The obtained results confirm the effectiveness of the proposed algorithm for creating heterogeneous groups. Although the number of grouping criteria is increased, the proposed algorithm forms always groups with the highest values of AID. 
Figure 3. AID's values of groups created by the proposed heterogeneous grouping algorithm compared with the grouping solution proposed by other researchers
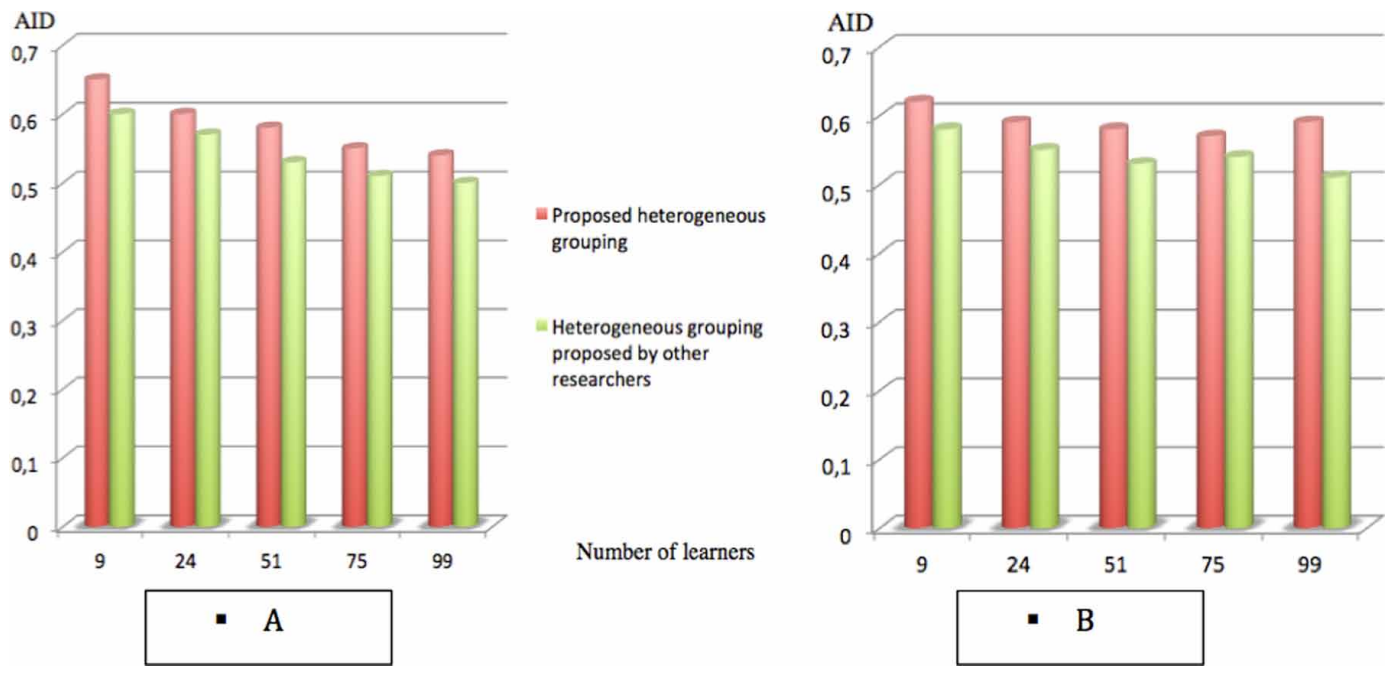

\section{Experimental Evaluation}

To confirm the results shown above, the researchers conducted an experimental study in which 54 students from a private secondary school were voluntarily participated. The participants consisted of 31 females and 23 males, aged between 16 to 17 years. The material chosen for this experiment was the French language, since the teachers of this material organize many interesting CL activities. Among the proposed works, the researchers chose a CL activity that asks students to make a reportage that presents a given city. The students of each group should search for the interesting information about the chosen city, visit it, obtain more information about it, and finally make a reportage that presents the visited city.

The experiment was lasted for two trimesters. During the first one, the researchers were working for collecting the different students' information, such as their biographic information, their learning styles, and their learning behaviors. Several techniques were used to obtain and save such information, like felling questionnaires, controlling collaborative activities, and testing individual competences. During this period, students were randomly assigned to small learning groups of three learners, in order to help them to be familiar with the MCSCL activities. The second trimester was dedicated for assessing the proposed group formation tool. To achieve this objective, two kinds of groups were created:

- (a) 9 control groups of 3 students were created by instructor;

- (b) 9 experiment groups of 3 students were automatically created by the proposed tool.

Even if the experiment groups were automatically created by the proposed grouping tool, but they were personalized by the instructor that introduced his grouping preferences (shown in table 3 ).

After forming the different learning groups, and before starting CL activities, students from control and experiment groups were asked to accomplish a pre-test of thirteen minutes, which will be compared with a post-test at the end of this experiment.

For both (control and experiment) groups, each participated learner was asked to complete with his/her colleagues several CL tasks, in different times and different places (in the classroom, and out of the classroom). First, learners of each group were asked to choose one city and to search the 
Table 3. Instructor's choices for forming learning groups

\begin{tabular}{|l|l|}
\hline Grouping type & Heterogeneous grouping \\
\hline Grouping criteria & $\begin{array}{l}\text { - Academic performance } \\
\text { - Communication with partners }\end{array}$ \\
\hline Group size & 3 members \\
\hline
\end{tabular}

interesting information about the historical places and the important points of interest of this city. Then, learners have to visit together the city, to use their mobile devices for finding more interesting places, to communicate with his/her group mates, and to take some photos and videos that can be add to their work. After the end of this activity, each learner should individually prepare his/her own reportage, and then the instructor evaluates the personal work of each learner. Then, the members of each group meet again and accomplish together the final reportage of the group and present it to their classmates. Three evaluation metrics were used by instructors to assess the presented works: (1) The language quality of the presented work, (2) The quality of the reportages in terms of the presented information, (3) The level of communication during the preparation and the presentation of the work.

Table 4 shows a comparison between the learning results of control and experimental groups. During the pre-assessment phase, one can remark that both groups have almost the same mean $(9.62$ / 20 for control group, and 9,29 / 20 for experimental group). This means that students of control groups have the same prerequisites for developing collaboratively reportage in French language as students of experimental groups. The low mean value of both groups (less than ten out of twenty) indicates a lack of students' cognitive skills and knowledge on the topic of reportages.

As for the Standard deviation results of pre assessment phase, one can remark that experimental groups have a greater value of standard deviation (2.93) compared to control groups $(1,59)$, meaning that experimental groups show more dispersion, and therefore these groups are more heterogeneous.

Regarding the post-assessment phase, one can remark that both groups have seen an increase in the mean values. But the rate of increase for experimental groups $(13.55-9.29=4.26$ as difference) was greater than that for control groups (1.72 as difference). This confirms that the proposed group formation solution had a significant impact on the learning achievement of learners. Therfore, one can say that the groups created by the proposed tool are more succefful than the control groups.

Finally, one can remark from the shown results a valuable decrease in the value of standard deviation of experimental groups between the pre-assessment and post assessment phases (from 2.93 to 1.18), and no significant change for control groups (small increase from 1.59 to 1.99). This

Table 4. Mean and Standard deviation of pre and post assessment of control and experimental groups

\begin{tabular}{|l|c|c|c|c|}
\hline & \multicolumn{2}{|c|}{ Control groups } & \multicolumn{2}{c|}{ Experimental groups } \\
\hline & Mean & Standard deviation & Mean & Standard deviation \\
\hline Pre-assessment & 9.62 & 1.59 & 9.29 & 2.93 \\
\hline Post-assessment & 11.34 & 1.99 & 13.55 & 1.18 \\
\hline
\end{tabular}

Table 5. Effect size when comparing control with experimental groups using Cohen's $d$ and Hedges' g measures

\begin{tabular}{|l|c|c|}
\hline & Cohen's D & Hedges' G \\
\hline Pre-assessment & 0.139 & 0.137 \\
Post-assessment & 1.35 & 1.331 \\
\hline
\end{tabular}


means that learning results from experimental groups have decreased the level of dispersion, and thus a reduction in the level of heterogenity between the group's memebers, which represents the main gole of CL.

For well analyzing the obtained results, the researchers have followed an "Effect size" measurement technique. It is a statistical method for measuring the magnitude of difference between the results of two groups (Kelley \& Preacher, 2012). In the case of this study, effect size helps researchers to know how much the learning outcomes of experimental groups are similar/different to those of the control groups.

As shown in table 5, the researchers have used two methods for measuring the effect size, Cohen's D and Hedges' G measures. (Cohen, 2013) suggested the following measures of similarity between groups:

- If $(\mathrm{D}<0.2)$ then the effect size is non significant. - If $(0.2 \leq \mathrm{D}<0.5)$ then the effect size is small.

- If $(0.5 \leq \mathrm{D}<0.8)$ then the effect size is medium. - If $(\mathrm{D} \geq 0.8)$ then the effect size is large.

By applying Cohen's D measures on these experiments, one can see that during the pre assessment period there was no significant effect size $(0.139<0.2)$. This means that students from both groups have similar prerequisites for learning. Conversely, during the post assessment period, there was a large effect size $(1.35>0.8)$. This indicates that there is a great superiority of the groups created automatically over the control groups in terms of learners' achievement.

In order to confirm the results obtained above, the researchers added another effect size evaluation method, which is Hedges' G measure. As same as Cohen's D, the Hedges' G values 0.2, 0.5, 0.8 indicate respectively small, medium, and large effect size. As shown in table 5, there is no great difference between (D) and $(G)$ obtained results ( 0.137 for pre-assessment, and 1.331 for post-assessment). Meaning that control and experimental groups have started their CL with similar prerequisites, but experimental groups finished their learning activities with large superiority than those of control groups. Thus, these results validate the effectiveness of the proposed group formation solution for creating successful groups.

\section{LIMITATION}

The main limitation encountered during the preparation of this study was related to the evaluation and comparison of the proposed solution with the existing ones. Because, only $2 \%$ of the existing studies has provided the source code of their group formation algorithms (Cruz \& Isotani 2014). Fortunately, the researchers of this study were able to obtain the algorithm's code sources, as well as, detailed information about the assessment process of the solutions proposed by (Huang $\& \mathrm{Wu}$, 2011) and (Zurita et al., 2005), which are considered as the two most important approaches existing in literature (Amara et al, 2016).

\section{CONCLUSION}

This paper shows a suitable group formation method that helps instructors to dynamically create learning groups in mobile computer supported collaborative learning (MCSCL) environments.

With this work, the authors provide the MCSCL's community with a valuable solution to form homogeneous, heterogeneous, and mixed learning groups, with the possibility to customize the grouping process according the learning's contexts, objectives, and needs.

Different evaluation techniques were used for assessing the proposed solution. For technical side, the proposed algorithm has demonstrated its efficiency in forming homogeneous and heterogeneous groups, whatever the size of groups and the used grouping criteria. For educational side, results have 
shown that experiment groups ensure always the best learning achievement compared with control groups.

Beside its benefits for learners, the proposed grouping solution represents a useful tool for instructors to continually evaluate and control their learners' development. It helps them to have detailed information about the personal, cognitive, social, and psychological progresses of learners. Furthermore, the proposed solution allows instructors to manage the learning groups whatever the place and time of learning.

Future research could address the integration of the proposed group formation process in the field of serious games. For instance, users could receive recommendations for players that share the same interests, which could help them to form gaming teams, or to discover new gaming communities. 


\section{REFERENCES}

Amara, S., Macedo, J., Bendella, F., \& Santos, A. (2016). Group Formation in Mobile Computer Supported Collaborative Learning Contexts: A Systematic Literature Review. Journal of Educational Technology \& Society, 19(2), 258-273.

Carro, R. M. (2008). Applications of adaptive hypermedia in education. In Computers and Education (pp. 1-12). Springer London. doi:10.1007/978-1-84628-929-3_1

Cohen, J. (2013). Statistical Power Analysis for the Behavioral Sciences. Routledge. doi:10.4324/9780203771587

Cruz, W. M., \& Isotani, S. (2014). Group formation algorithms in collaborative learning contexts: A systematic mapping of the literature. In CYTED-RITOS International Workshop on Groupware (pp. 199-214). Springer. doi:10.1007/978-3-319-10166-8_18

Dillenbourg, P. (1999). What do you mean by collaborative learning? In P. Dillenbourg (Ed.), Collaborativelearning: Cognitive and Computational Approaches (pp. 1-19). Elsevier.

El-Bishouty, M. M., Ogata, H., Rahman, S., \& Yano, Y. (2010). Social Knowledge Awareness Map for Computer Supported Ubiquitous Learning Environment. Journal of Educational Technology \& Society, 13(4), $27-37$.

Hsieh, J. C., Chen, C. M., \& Lin, H. F. (2010). Social interaction mining based on wireless sensor networks for promoting cooperative learning performance in classroom learning environment. In The 6th IEEE International Conference on Wireless, Mobile, and Ubiquitous Technologies in Education (pp. 219-221). Los Alamitos, CA: IEEE.

Huang, J. J., Yang, S. J., Huang, Y. M., \& Hsiao, I. Y. (2010). Social Learning Networks: Build Mobile Learning Networks Based on Collaborative Services. Journal of Educational Technology \& Society, 13(3), 78-92.

Huang, Y. M., \& Wu, T. T. (2011). A Systematic approach for learner group composition utilizing U-learning portfolio. Journal of Educational Technology \& Society, 14(3), 102-117.

ITU. (2018). International Telecommunication Union agency. Retrieved from: https://www.itu.int/en/ITU-D/ Statistics/Documents/Global\%20ICT\%20Developments\%202001-2018\%20-\%20original.jpg

Jain, Y. K., \& Bhandare, S. K. (2011). Min max normalization based data perturbation method for privacy protection. International Journal of Computer \& Communication Technology, 2(8), 45-50.

Johnson, D. W., \& Johnson, R. T. (1994). Leading the Cooperative School. Interaction Book Company.

Kelley, K., \& Preacher, K. J. (2012). On effect size. Psychological Methods, 17(2), 137-152. doi:10.1037/ a0028086 PMID:22545595

Lai, E. R. (2011). Collaboration: A literature review (Vol. 2). Pearson Research Report.

Mballo, M. H. W., Diop, A., Hotte, R., \& Niang, I. (2017). Forming groups of mobile learners that promote collaborative learning supported by mobile devices. In Innovation and Interdisciplinary Solutions for Underserved Areas (pp. 56-65). Springer. doi:10.1007/978-3-319-72965-7_5

Messeguer, R., Medina, E., Royo, D., Navarro, L., \& Juárez, J. P. (2010). Group Prediction in Collaborative Learning. In 2010 Sixth international conference on intelligent environments (pp. 350-355). IEEE. doi:10.1109/ IE.2010.71

Mujkanovic, A., Lowe, D. B., \& Willey, K. (2012). Adaptive group formation to promote desired behaviours. In AAEE-Annual Conference of Australasian Association for Engineering Education (pp. 850-858). Swinburne University of Technology.

Roger, T., \& Johnson, D. W. (1994). An overview of cooperative learning. Creativity and collaborative learning, $1-21$.

Tan, Q., Jeng, Y. L., \& Huang, Y. M. (2010). A collaborative mobile virtual campus system based on locationbased dynamic grouping. In 2010 10th IEEE International Conference on Advanced Learning Technologies (pp. 16-18). IEEE. doi:10.1109/ICALT.2010.11 
Webb, N. M., Nemer, K. M., Chizhik, A. W., \& Sugrue, B. (1998). Equity issues in collaborative group assessment: Group composition and performance. American Educational Research Journal, 35(4), 607-651. doi:10.3102/00028312035004607

Yadegaridehkordi, E., Shuib, L., Nilashi, M., \& Asadi, S. (2019). Decision to adopt online collaborative learning tools in higher education: A case of top Malaysian universities. Education and Information Technologies, 24(1), 79-102. doi:10.1007/s10639-018-9761-z

Yamamoto, N., \& Uchida, N. (2018). Dynamic group formation for an active learning system using Smartphone to improve learning motivation. In International Conference on Innovative Mobile and Internet Services in Ubiquitous Computing (pp.183-189). Springer. doi:10.1007/978-3-319-93554-6_16

Yin, C., Dong, Y., Tabata, Y., \& Ogata, H. (2012). Recommendation of helpers based on personal connections in mobile learning. In 2012 Seventh IEEE International Conference on Wireless, Mobile and Ubiquitous Technology in Education. (pp.137-141). IEEE. doi:10.1109/WMUTE.2012.32

Zurita, G., Nussbaum, M., \& Salinas, R. (2005). Dynamic grouping in collaborative learning supported by wireless handhelds. Journal of Educational Technology \& Society, 8(3), 149-161.

Sofiane Amara is a researcher at the informatics department, university of science and technology of Oran (USTO), Algeria. He received his BSc and MSc in Computer Science from the university of Mostaganem, Algeria. He is pursuing the PhD degree in the field of Information Systems Engineering at the Informatics department, university of USTO. At the same time, he has been working with CCN (Computer Communications and Networks) research group from the university of Minho (Portugal), and INETI (Ingénierie Educative et Techniques Informatiques) group from the university of USTO. His current interests are focused on collaborative learning, technology enhanced learning, adaptivity and personalization.

Fatima Bendella received an engineer diploma in informatics from the University of Oran and a PhD in computer science from the University of Science and Technology of Oran, Algeria in 2005. She has been involves in research of knowledge management systems, learning environments, collaborative learning, ontology's and embodied agents. She has also investigated the domain of serious games for medical domain. She is currently a professor in the department of computer science at the University of Sciences and Technology of Oran Mohamed Boudiaf.

Joaquim Henriques Macedo, is an Assistant Professor at Department of Informatics, University of Minho, Portugal, where he develops teaching and research activities in the fields of Computer Networks and Computer Communications since 1988. As a researcher, he currently integrates the Computer Communications and Networks $(\mathrm{CCN})$ research group, at Centro Algoritmi, University of Minho. He obtained a PhD Degree in Information Retrieval in 2002 at the same University. He supervised more than two dozen Master students (eighteen completed) and eight PhD students (4 with PhD completed). He also supervised dozens of bachelor's theses. Prof. Joaquim Macedo taught courses on Information Retrieval, Network and Communications, and Virtualized Networks in the Integrated Masters in Computer Engineering, Telecommunications and Computer Engineering, and Biomedical Engineering and in the Masters in Computer and Network Engineering and Telematic Services. In terms of publications, Joaquim published more than 80 between book chapters, articles in conferences and journals, scientific reports, pedagogical manuals, and articles for dissemination.

Alexandre J. T. Santos (IEEE SM-10) is Associate Professor with Habilitation in Informatics at the Informatics Department, Engineering School, University of Minho. He his Senior Researcher, and has been Associate Director of R\&D Centro ALGORITMI in 2013-2016. He is now on the lead of the CCPM, Computer Communications and Pervasive Media research line and also of the Computer Communicationds and Networks (CCN) Laboratory. He received his PhD in Computer Communications from the University of Minho in 1996. He has several participations in R\&D international projects on computer communications, protocols and Internet based services. He has authored or co-authored numerous scientific papers at international refereed Journals and Conferences (with some best paper awards). He has been Project Evaluator for International and National R\&D funding institutions and has served a TPC member for several IEEE, ACM and IFIP sponsored international conferences. Alexandre J. T. Santos is member by invitation of the Academic Committee of the "Magister en Redes de Datos", Facultad de Informática, Universidad Nacional de La Plata (UNLP), Argentina and also member of the Scientific Advisory Board of the Research Centre CIICIPL, Centro de Investigação em Informática e Comunicações, Instituto Politécnico de Leiria, Portugal. Also a member of the Scientific Committee from the MAP-Tele joint PhD Program of the Universities of Minho, Aveiro and Porto. He is IEEE Senior Member from IEEE Computer Society and member of IEEE Vehicular Technology Society and IEEE Communications Society. 